\title{
Kontribusi Usahatani Cengkeh terhadap Pendapatan Total Keluarga Petani Cengkeh di Desa Pengeragoan Kecamatan Pekutatan Kabupaten Jembrana
}

\author{
BELLO ARDA UTAMA, I KETUT BUDI SUSRUSA, \\ I DEWA GEDE RAKA SARJANA
}

\author{
Program Studi Agribisnis, Fakultas Pertanian, Universitas Udayana \\ Jalan PB. Sudirman Denpasar 80323 \\ Email: belloarda@gmail.com \\ kbsusrusa@gmail.com
}

\begin{abstract}
Contribution of Clove Farming to Farmers Household Income in Pengeragoan Village Pekutatan Pekutatan District Jembrana Regency
\end{abstract}

Clove is one of agricultural commodities that is commonly found in Pengeragoan Village, Pekutatan District, Jembrana Regency. The Purpose of this research is to find out the farming analysis clove and the large determine contribution of clove farming to the income of farm household in Pengeragoan Village. The sampling technique used was proportional random sampling and samples taken randomly to select the sample by lottery method with 34 clove farmers. The data collection in this study was conducted from early September to the end of September 2017. Research used farming analysis to calculate net income of clove farmers during one year in 2016. Result of the analysis showed that sources of farmer income range from plantation of clove, coconut, cocoa, and banana whereas the non-farm income ranges from trader, servant, and private employees. Contribution of clove farm reaches $80,05 \%$ of total income of farmer household $\operatorname{Rp} 82.346 .949,00 /$ year with an average income of $\mathrm{Rp} 65.917 .472,00 /$ year.

Keywords: clove, income, contribution,.....

\section{Pendahuluan}

\subsection{Latar Belakang}

Cengkeh memiliki peranan penting dalam pembangunan perkebunan khususnya dan pembangunan nasional pada umumnya. Cengkeh berkontribusi nyata dalam penyediaan kebutuhan bahan baku bagi industri rokok kretek, penyedia lapangan kerja, peningkatan devisa negara, peningkatan pendapatan petani, dimana saat ini sebagian besar hasil cengkeh (95\%) digunakan sebagai bahan baku pembuatan rokok kretek, sisanya cengkeh dimanfaatkan untuk industri makanan dan obat-obatan, sehingga cengkeh dapat dikatakan memiliki peran penting dalam perekonomian nasional (Nurdjanna, 2007). Komoditi cengkeh adalah salah satu komoditi perkebunan yang memiliki potensi dikembangkan. Total luas areal perkebunan cengkeh di Provinsi Bali adalah 15.668 hektar dengan total hasil produksi cengkeh pada tahun 2015 sebesar 
5.871 ton. Perkebunan cengkeh Provinisi Bali berpusat pada tiga kabupaten yakni Kabupaten Buleleng, Kabupaten Jembrana, dan Kabupaten Tabanan dengan total 87,9 $\%$ dari total luas perkebunan cengkeh Provinsi Bali. Luas lahan perkebunan cengkeh di Kabupaten Jembrana 3.447 hektar atau $22 \%$ dari total luas areal cengkeh Provinsi Bali. Desa Pengeragoan adalah salah satu desa di Kecamatan Pekutatan, Kabupaten JembranaKomoditi cengkeh di Desa Pengeragoan dijadikan andalan sumber pendapatan keluarga. Perkebunan cengkeh di Desa Pengeragoan khususnya 5 tahun terakhir dari tahun 2011 sampai tahun 2016 mengalami kenaikan dan penurunan luas lahan yang diikuti dengan produksi cengkeh yang berfluktuasi.

Berdasarkan perkembangan luas areal dan produksi cengkeh selama lima tahun terakhir di Desa Pengeragoan hanya terjadi sekali penurunan luas areal di tahun 2013, sisanya mengalami peningkatan. Hal ini mengindikasikan bahwa ada kecenderungan petani di Desa Pengeragoan meningkatkan luas areal tanaman cengkehnya. Kecenderungan meningkatnya luas areal cengkeh ini tentunya dapat diartikan petani Desa Pengeragoan memiliki harapan pada komoditi cengkeh, tetapi dengan meningkatnya kepercayaan petani terhadap komoditi cengkeh tentunya sangat rentan terhadap risiko karena terjadinya fluktuasi harga yang merugikan petani ketika musim panen tiba. Berdasarkan uraian diatas, maka peneliti tertarik untuk mengadakan penelitian mengenai besarnya kontribusi usahatani cengkeh terhadap pendapatan total keluarga petani cengkeh di Desa Pengeragoan, Kecamatan Pekutatan, Kabupaten Jembrana.

\subsection{Rumusan Masalah}

Berdasarkan uraian latar belakang, maka dapat ditarik beberapa rumusan masalah sebagai berikut.

1. Bagaimanakah analisis usahatani cengkeh di Desa Pengeragoan, Kecamatan Pekutatan, Kabupaten Jembrana?

2. Berapakah kontribusi usahatani cengkeh terhadap pendapatan keluarga petani cengkeh di Desa Pengeragoan, Kecamatan Pekutatan, Kabupaten Jembrana?

\subsection{Tujuan Penelitian}

Berdasarkan permasalahan di atas maka tujuan dalam penelitian ini adalah sebagai berikut.

1. Untuk mengetahui pendapatan usahatani cengkeh di Desa Pengeragoan, Kecamatan Pekutatan, Kabupaten Jembrana.

2. Untuk mengetahui kontribusi usahatani cengkeh terhadap pendapatan keluarga petani cengkeh di Desa Pengeragoan, Kecamatan Pekutatan, Kabupaten Jembrana. 


\section{Metode Penelitian}

\subsection{Lokasi dan Waktu Penelitian}

Penelitian ini dilaksanakan di Desa Pengeragoan, Kecamatan Pekutatan, Kabupaten Jembrana, Provinsi Bali dari tanggal 15 Agustus s.d 6 September 2017. Pemilihan lokasi penelitian dilakukan dengan sengaja menggunakan metode purposive sampling. Metode purposive yaitu suatu metode penentuan daerah penelitian yang sebelumnya ditentukan atas pertimbangan-pertimbangan tertentu (Notoatmodjo, 2010). Pemilihan Desa Pengeragoan dilakukan dengan pertimbangan bahwa Desa Pengeragoan merupakan sentra tanaman cengkeh di Kecamatan Pekutatan.

\subsection{Jenis dan Sumber Data}

Jenis data yang digunakan dalam penelitian ini adalah data kuantitatif dan data kualitatif. Data kualitatif merupakan data berupa penjelasan dari masalah yang diteliti di lokasi penelitian seperti gambaran umum Desa Pengeragoan dan data kuantitatif merupakan data yang berupa angka-angka. Sumber data yang digunakan dalam penelitian ini adalah data primer dan data sekunder. Data primer berupa data yang bersumber dari hasil langsung penelitian dengan petani dan data sekunder tidak langsung seperti melalui literatur.

\subsection{Metode Pengmpulan Data}

Pengumpulan data pada penelitian ini mengunakan survey usahatani. Survey usahatani dilakukan dengan membuat kuisioner berisikan daftar pertanyaan kepada responden terkait dengan sumber pendapatan masing-masing rumah tangga petani, serta data usahatani seperti jumlah produksi, penggunaan dan jumlah input produksi, harga masing-masing input produksi, biaya tenaga kerja, penerimaan usahatani cengkeh, dan usahatani lainnya (kelapa, kakao, dan pisang) produksi 2016.

\subsection{Jenis dan Pengkuran Variabel dan Analisis Data}

Variabel dalam penelitian ini yaitu besar pendapatan total keluarga petani cengkeh dan kontribusi usahatani cengkeh terhadap pendapatan total keluarga petani.

a. Analisis Sumber Pendapatan Petani

Analisis sumber pendapatan petani digunakan untuk mengetahui total pendapatan rumah tangga petani. Cara menghitung analisis ini dengan menjumlahkan seluruh pendapatan keluarga petani.

$$
\prod_{\mathrm{rt}}=\prod_{\mathrm{uc}}+\prod_{\mathrm{ul}}+\prod_{\mathrm{n}}
$$




\section{Keterangan:}

$\prod_{\mathrm{rt}} \quad$ : Pendapatan rumah tangga $(\mathrm{Rp} / \mathrm{th})$

$\prod_{\text {uc }}:$ Pendapatan usahatani cengkeh (Rp/th)

$\prod_{\mathrm{ul}} \quad$ : Pendapatan usahatani lainnya (Rp/th)

$\prod_{\text {nu }}:$ Pendapatan non usahatani $(\mathrm{Rp} / \mathrm{th})$

\section{b. Analisis Usahatani Cengkeh}

Analisis Usahatani Cengkeh bertujuan untuk mengetahui besar keuntungan yang diperoleh dari usahatani cengkeh yang dilakukan. Adapun cara menghitungnya adalah total pemasukan dikurangi dengan total biaya.

$$
\prod_{\mathrm{uk}}=\mathrm{TR}-\mathrm{TC} .
$$

Keterangan :

$\prod_{\mathrm{uk}}$ : Pendapatan usahatani Cengkeh tahun $2016(\mathrm{Rp} / \mathrm{th})$

TR : Total penerimaan (total revenue) Cengkeh tahun 2016

TC : Total biaya (total cost) Cengkeh tahun 2016

c. Analisis Usahatani Lainnya

Analisis usahatani lainnya (Kelapa, Kakao dan Pisang) bertujuan untuk mengetahui besar keuntungan yang diperoleh dari usahatani kelapa, kakao, dan pisang yang dilakukan. Adapun cara menghitungnya adalah total pemasukan dikurangi dengan total biaya.

$$
\prod_{\mathrm{uk}}=\mathrm{TR}-\mathrm{TC} \text {. }
$$

Keterangan:

$\prod_{\mathrm{uk}}:$ Pendapatan usahatani lainnya tahun $2016(\mathrm{Rp} / \mathrm{th})$

TR : Total penerimaan (total revenue) usahatani lainya tahun $2016(\mathrm{Rp} / \mathrm{th})$

TC : Total biaya (total cost) usahatani lainnya tahun 2016 (Rp/th)

d. Pendapatan Non Usahatani

Pendapatan non usahatani dihitung mengunakan analisis kuantitatif dengan menjumlahkan seluruh pendapatan keluarga yang bersumber dari non usahatani.

$$
\prod_{\mathrm{nu}}=\prod_{\mathrm{bb}}+\prod_{\mathrm{pdg}}+\prod_{\mathrm{pgw}}
$$

Keterangan:

$\prod_{\text {nu }}:$ Pendapatan non usahatani (Rp/th)

$\prod_{\text {tbb }}:$ Pendapatan buruh bangunan (Rp/th)

$\prod_{\text {pdg }}:$ Pendapatan Pedagang (Rp/th)

$\prod_{\text {pgw }}:$ Pendapatan Pegawai (Rp/th) 


\section{e. Kontribusi}

Kontribusi digunakan untuk mengetahui seberapa besar pengaruh satu pendapatan (\%) terhadap pendapatan total dari petani. Adapun cara menghitungnya dengan membagi pendapatan yang ingin diketahui kontribusinya dengan pendapatan total.

$$
K u c=\frac{\prod u c(R p)}{\prod r t(R p)} \mathrm{X} 100 .
$$

Keterangan:

Kuc : Kontribusi usahatani cengkeh (100\%)

$\prod_{\text {uc }} \quad$ : Pendapatan usahatani cengkeh $(\mathrm{Rp} / \mathrm{th})$

$\prod_{\mathrm{rt}} \quad$ :Pendapatan rumah tangga $(\mathrm{Rp} / \mathrm{th})$

\section{Hasil dan Pembahasan}

\subsection{Karakteristik Responden}

Berdasarkan hasil penelitian, rentang usia petani cengkeh Desa Pengeragoan 33 s.d 75 tahun, dengan rata-rata usia petani 53 tahun, dimana rata-rata tingkat pendidikan petani di Desa Pengeragoan sampai pada tingkat pendidikan formal yang sedang atau sampai Sekolah Menengah Pertama (SMP). Karakteristik jumlah anggota keluarga menunjukkan bahwa kisaran jumlah 4 s.d 6 menjadi jumlah anggota keluarga yang terbanyak dengan 22 responden dengan persentase 64,71\%. Petani cengkeh di Desa Pengeragoan menjadikan bertani menjadi pekerjaan utama, sedangkan untuk pekerjaan sampingan sebagian besar petani cengkeh di Desa Pengeragoan tidak memiliki pekerjaan sampingan atau hanya berfokus pada pekerjaan pokok sebagai petani dengan persentase sebesar $61,76 \%$. Petani dominan berusahatani pada lahan 0,5 ha s.d. 2,0 ha dengan persentase $88,24 \%$. Petani dengan luas garapan kurang dari 0,5 ha dan lebih dari 2,0 ha masing-masing sebesar $2,94 \%$ dan $8,82 \%$.

\subsection{Pendapatan Usahatani Cengkeh}

Pendapatan usahatani cengkeh di Desa Pengeragoan Rp 483.549,53/are/tahun. Adapun hasil analisis pendapatan usahatani cengkeh di Desa Pengeragoan tahun 2016 dapat dilihat pada tabel 1 . 
Tabel 1.

Rata-rata Pendapatan Usahatani Cengkeh di Desa Pengeragoan Tahun 2016 Per Luas Garapan

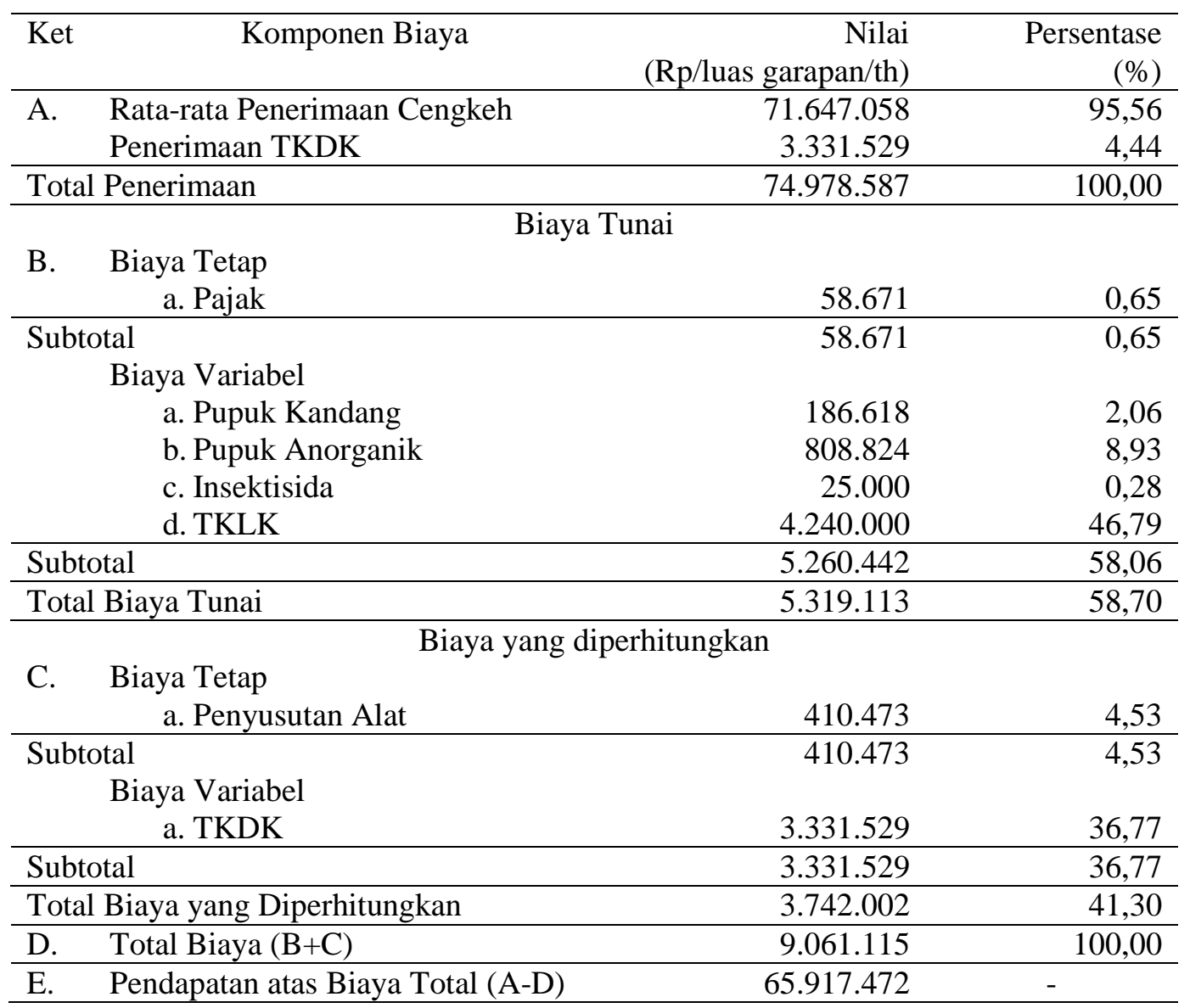

Sumber: Data primer diolah (2017)

Hasil dari analisis usahatani cengkeh adalah total penerimaan yang diterima petani cengkeh dari produksi usahatani cengkeh baik itu dari penjualan bunga cengkeh ditambah penjualan tangkai cengkeh ataupun petani yang mengontrakkan cengkehnya adalah rata-rata sebesar $\mathrm{Rp} 74.978 .587,00 /$ th dan total biaya usahatani cengkeh yang dikeluarkan petani cengkeh dalam tahun 2016, rata-rata sebesar Rp 9.061.115,00/th. Rata-rata pendapatan bersih yang diterima petani cengkeh di Desa Pengeragoan setelah dikurangkan dengan total biaya adalah sebesar Rp 65.917.472,00/th.

\subsection{Sistem Kontrak Panen Cengkeh}

Petani cengkeh di Desa Pengeragoan dalam berusahatani cengkeh ada yang melaksanakan kegiatan panennya sendiri dan yang mengontrakkan kebun cengkehnya ketika panen. Distribusi bentuk penerimaan petani cengkeh di Desa Pengeragoan yang menjual cengkeh kering dan mengontrakkan cengkehnya dapat dilihat pada tabel 2 . 
Tabel 2.

Distribusi Bentuk Penerimaan Petani Cengkeh di Desa Pengeragoan Tahun 2016

\begin{tabular}{cccc}
\hline No & Bentuk penerimaan & Jumlah (Orang) & Persentase (\%) \\
\hline 1 & Menjual cengkeh kering & 14 & 41 \\
2 & Dikontrakkan & 20 & 59 \\
\hline & Jumlah & 34 & 100 \\
\hline
\end{tabular}

Sumber: Data Primer diolah (2017)

Lebih banyak responden petani cengkeh di Desa Pengeragoan yang mengontrakkan cengkehnya dengan persentase $59 \%$, sedangkan petani yang menjual cengkeh kering dan melakukan panen dan pasca panen sendiri sebesar $41 \%$. Hal ini dapat diartikan lebih banyak petani yang enggan mengambil resiko melakukan proses panen dan pasca panennya. Kecendrungan petani cengkeh untuk mengontrakkan cengkehnya karena waktu panen komoditi cengkeh yang serempak di antara Bulan Juli sampai dengan September sehingga menyulitkan petani dalam mencari tenaga kerja untuk memanen komoditi cengkehnya.

\subsection{Pendapatan Usahatani Lainnya}

Rata-rata penerimaan atas usahatani kelapa adalah sebesar Rp 5.970.941,00 dengan total biaya pada usahatani kelapa sebesar Rp 857.233,00 Pendapatan rata-rata yang diperoleh dari usahatani kelapa adalah $\mathrm{Rp} 5.113 .708,00 /$ th. Besarnya biaya usahatani kelapa sebagian besar untuk biaya tenaga kerja karena kurangnya akses jalan mengantar kelapa dari kebuk menuju jalan.

Varietas kakao yang diusahatanikan petani di Desa Pengeragoan adalah varietas trinitario atau kakao mulia. Petani rata-rata melakukan pemanenan dua minggu sekali dengan rata-rata umur tanaman 15 tahun. Rata-rata penerimaan yang diperoleh petani atas usahatani kakao adalah Rp 5.228.236,00 dengan rata-rata biaya yang dikeluarkan oleh petani adalah sebesar Rp 1.178.114,00. Pendapatan rata-rata yang diperoleh dari usahatani kakao adalah Rp 4.050.122,00/th.

Varitas pisang yang diusahakan petani adalah pisang mas dan pisang susu, petani melakukan pemanenan minimal dua kali dalam setahun. Rata-rata penerimaan yang diperoleh petani pada usahatani pisang adalah Rp 1.643.265,00 dengan rata-rata biaya yang dikeluarkan oleh petani adalah sebesar Rp 518.796,00. Pendapatan rata-rata yang diperoleh dari usahatani pisang adalah $\mathrm{Rp} 1.124 .469,00 /$ th.

Rata-rata pendapatan petani yang bersumber dari usahatani selain cengkeh yang meliputi usahatani kelapa, kakao dan pisang adalah sebesar Rp 10.288.301,00/th

\subsection{Pendapatan Non Usahatani}

Petani di Desa Pengeragoan memiliki pendapatan non usahatani. Pendapatan non usahatani petani cengkeh di Desa Pengeragoan bersumber dari beberapa jenis mata pencaharian diantaranya pedagang, pegawai, dan swasta. Adapun penjelasannya dapat dilihat pada tabel 3 . 
Tabel 3.

Distribusi Pekerjaan Petani dari Non Usahatani di Desa Pengeragoan Tahun 2016

\begin{tabular}{llcc}
\hline No & Pekerjaan Non Usahatani & Jumlah (orang) & Persentase \\
& & & \\
\hline 1 & Pedagang & 8 & 23,53 \\
2 & Pegawai & 4 & 11,76 \\
3 & Swasta & 1 & 2,94 \\
4 & Tidak punya & 21 & 61,76 \\
\hline & Jumlah & 34 & 100,00 \\
\hline
\end{tabular}

Sumber: Data primer diolah (2017)

Rata-rata pendapatan dari non usahatani sebesar Rp 6.141.176/th. Sebanyak $61,76 \%$ petani tidak mempunyai pekerjaan non usahatani. Pekerjaan non usahatani tertinggi adalah sebagai pedagang dengan angka 23,53\%. Pendapatan yang di peroleh dari non usahatani akan dikontribusikan pada rumah tangga petani cengkeh di Desa Pengeragoan guna memenuhi kebutuhan petani.

\subsection{Kontribusi Usahatani Cengkeh terhadap Pendapatan Total Keluarga}

Sumber pendapatan petani cengkeh di Desa Pengeragoan secara umum ada tiga sumber pendapatan yaitu usahatani cengkeh, usahatani lainnya yang meliputi usahatani kelapa, kakao, dan pisang, serta non usahatani yang meliputi pedagang, pegawai dan swasta dengan kontribusi masing-masing sebagai berikut.

\section{Tabel 4.}

Total Rata-rata Pendapatan Keluarga Petani Pada Usahatani Cengkeh, Usahatani Lainnya, dan Non Usahatani di Desa Pengeragoan Tahun 2016

\begin{tabular}{cccc}
\hline No & \multicolumn{1}{c}{ Sumber } & Rata-rata Pendaptan $(\mathrm{Rp})$ & Persentase $(\%)$ \\
\hline 1 & Cengkeh & 65.917 .472 & 80,05 \\
2 & Usahatani Lainnya & 10.288 .301 & 12,49 \\
3 & Non Usahatani & 6.141 .176 & 7,46 \\
\hline & Total & 82.346 .949 & 100,00 \\
\hline
\end{tabular}

Besarnya total pendapatan rumah tangga petani cengkeh di Desa Pengeragoan sebesar Rp 82.346.949,00/th. Pendapatan usahatani cengkeh menjadi pendapatan tertinggi rata-rata pendapatan sebesar $\mathrm{Rp} 65.917 .472,00 /$ th dengan persentase $80,05 \%$, Pada sumber pendapatan usahatani laiannya memiliki rata-rata pendapatan Rp $10.288 .301,00 /$ th dengan persentase $12,49 \%$, sedangkan pada sumber pendapatan non usahatani diketahui memiliki rata-rata pendapatan sebesar Rp 6.141.176/th dengan persentase 7,46\%. Berdasarkan penjelasan di atas menunjukkan bahwa usahatani cengkeh memiliki kontribusi paling tinggi terhadap pendapatan total petani di Desa Pengeragoan, sedangkan sumber pendapatan non usahatani memiliki kontribusi terkecil terhadap pendapatan total rumah tangga petani. 


\section{Simpulan dan Saran}

\subsection{Simpulan}

Berdasarkan hasil analisis dan pembahasan yang telah dilakukan, maka dapat disimpulkan;

1. Rata-rata penerimaan dari usahatani cengkeh, baik itu dari penjualan bunga cengkeh ditambah penjualan tangkai cengkeh ataupun petani yang mengontrakkan cengkehnya adalah sebesar $\operatorname{Rp} 74.978 .587,00 /$ th dan total biaya usahatani cengkeh yang dikeluarkan pada tahun 2016, rata-rata sebesar Rp 9.061.115,00/th. Rata-rata pendapatan bersih yang diterima petani cengkeh di Desa Pengeragoan setelah dikurangkan dengan total biaya adalah sebesar Rp 62.585.943,00/th.

2. Total pendapatan rumah tangga petani cengkeh di Desa Pengeragoan sebesar Rp $82.346 .949,00 /$ th. Pada sumber pendapatan usahatani lainnya memiliki rata-rata pendapatan Rp 10.288.301,00/th dengan persentase 12,49\%, sedangkan pada sumber pendapatan non usahatani diketahui memiliki rata-rata pendapatan sebesar Rp 6.141.176/th dengan persentase 7,46\%. Pendapatan usahatani cengkeh menjadi pendapatan tertinggi. Rata-rata pendapatan usahatani cengkeh sebesar Rp 65.917.472,00/th. Jadi, kontribusi usahatani cengkeh terhadap pendapatan total keluarga petani adalah sebesar $80,05 \%$.

\subsection{Saran}

Berdasarkan hasil pembahasan dan kesimpulan yang diperoleh maka saran yang dapat disampaikan dalam penelitian ini;

1. Petani diharapkan memiliki upaya-upaya tertentu agar kompetensi petani dan anggota keluarga petani yang masih kurang (lemah) dapat dioptimalkan dalam berkegiatan usahatani seperti kompetensi dalam kegiatan panen usahatani cengkeh melalui pendidikan non formal seperti pelatihan agar bisa memaksimalkan tenaga kerja dalam keluarga (TKDK).

2. Petani di Desa Pengeragoan disarankan untuk mengurangi ketergantungan terhadap komoditi cengkeh dengan meningkatkan usahatani lainnya serta mencari tambahan pemasukan dari pekerjaan non usahatani.

3. Perlu adanya penelitian lebih lanjut terhadap perbedaan keuntungan yang didapatkan petani cengkeh yang mengurus panen cengkehnya sendiri dengan petani yang mengontrakkan panen cengkehnya.

\section{Ucapan Terimakasih}

Ucapan terimakasih ini penulis tunjukan kepada seluruh responden petani cengkeh

di Desa Pengeragoan, Kecamatan Pekutatan, Kabupaten Jembrana, yang telah membantu dalam pelaksanaan penelitian hingga karya ilmiah ini dapat dipublikasikan di e-jurnal. 


\section{Daftar Pustaka}

Antara, I Made. 2010. Bahan Ajar Metodologi Penelitian Sosek. Program studi Agribisnis. Fakultas Pertanian. Universitas Udayana. Denpasar.

Badan Pusat Statistik Provinsi Bali. 2016. Statistik Hortikultura Provinsi Bali. BPS. Bali.

Badan Pusat Statistik. 2014. Statistik Pemuda Indonesia 2014. http:www.bps.go.id. Sumber Daya Manusia Pemuda Indonesia Statistik 2014. Di unduh 25 Mei 2017

Gustiyana, H. 2004. Analisis Pendapatan Usahatani Untuk Produk Pertanian. Selemba empat. Jakarta.

Hernanto, F. 1988. Ilmu Usaha Tani. Penebar Swadaya. Jakarta.

Nurdjannah, N. 2007. Diversifikasi Penggunaan Cengkeh, Bogor: Balai Besar Penelitian dan Pengembangan Pasca Panen Pertanian Indonesian Center for Agricultural Postharvest Research and Development.

Siregar. A.R. 2011. Analisis Disparitas Harga dan Potensi Persaingan Tidak Sehat Pada Distribusi Cengkeh Jurnal Agribisnis Vol 10 No.3.

Soekartawi, 1984. Ilmu Usahatani dan Penelitian Untuk Pengembangan Petani Kecil. Jakarta.

Soekartawi. 1994. Analisis Usaha Tani. Penerbit Universitas Indonesia. Jakarta.

Soekartawi. 1995. Analisis Usahatani. UI Press. Jakarta.

Soekartawi. 2006. Analisis Usahatani. UI Press. Jakarta. 